\title{
Genetic variation for growth at one and two summers of age in the common carp (Cyprinus carpio L.): Heritability estimates and response to selection
}

\author{
Marc Vandeputte ${ }^{a, b}$ *, Martin Kocour ${ }^{c}$, Stéphane Mauger ${ }^{a}$, Marek Rodina ${ }^{c}$, Amandine \\ Launay ${ }^{\mathrm{a}}$, David Gela ${ }^{\mathrm{c}}$, Mathilde Dupont-Nivet ${ }^{\mathrm{a}}$, Martin Hulak ${ }^{\mathrm{c}}$ and Otomar Linhart ${ }^{\mathrm{c}}$

\footnotetext{
a INRA UR544 Unité de Génétique des Poissons, F-78350 Jouy-en-Josas, France

${ }^{\mathrm{b}}$ IFREMER, chemin de Maguelone, F-34250 Palavas les Flots, France

c University of South Bohemia, Research Institute of Fish Culture and Hydrobiology, Zátiší 728/II, 38925 Vodňany, Czech Republic
}

*: Corresponding author : Vandeputte M., email address : Marc.Vandeputte@jouy.inra.fr

\begin{abstract}
:
We estimated the heritability of growth-related traits (weight and length at ages one summer, first spring and two summers) in a synthetic mirror carp strain (HSM) in the Czech Republic. The four generation pedigree was obtained from parentage assignment of three factorial mating designs with microsatellite markers, and included 195 fish without phenotypes (48 G0, $147 \mathrm{G} 1$ ) and 1321 fish with phenotypes (674 G2, $647 \mathrm{G} 3$ ). Animal model heritability estimates over generations were in the range $0.21-0.33$ for length and in the range $0.31-0.44$ for weight. The genetic correlation between length and weight was high (0.97). The correlations between growth measurements in the first and in the second summer of age were moderate to low (0.34-0.67). Divergent selection for length at two summers of age was performed on G2 fish, and response to selection was evaluated by comparing the offspring of the selected sires in G3, in a communal test where genetic groups were identified by microsatellite parentage assignment. The response to upwards selection was moderate and indicated a realized heritability value of 0.24 to 0.34 . No response to downwards selection was observed. We conclude that although selection for growth seems to be feasible in common carp, it would be a longterm process before results are visible.
\end{abstract}

Keywords: Common carp; Cyprinus carpio; Heritability; Growth; Selection; Selection response; Realized heritability; Parentage assignment; Microsatellites; Performance; Quantitative genetics 


\section{Introduction}

The common carp, Cyprinus carpio, is a major fish species in world aquaculture production (FAO, 2003) cultured exclusively under traditional extensive or semi-intensive pond management, where fish growth is highly dependent (50\% and more) on natural food (plankton and benthos). Hence, environmental conditions have a major impact on the performance of common carp, and much attention has been given to the optimization of pond management (see Horvath et al., 1992). Genetic improvement could be a complementary way to increase the effectiveness of carp culture.

Genetic improvement of quantitative traits in carp has proceeded through selection (Moav and Wohlfarth, 1976), genome manipulations (Cherfas et al., 1996; Kocour et al., 2003) and crossbreeding (e.g. Bakos and Gorda, 1995; Bialowas, 1991; Gross and Wohlfarth, 1994; Wohlfarth, 1993, see review by Hulata, 1995). Presently, the only widely applied method in common carp culture is intra-specific crossbreeding (Kocour et al., 2005). Concerning within-breed selection, a well documented experiment (but still controversial - see Kinghorn, 1983) found that mass selection for growth was ineffective (Moav and Wohlfarth, 1976). Estimated heritabilities for growth traits range from 0.0 to 0.5 (Vandeputte, 2003, for a review), but some of those past heritability estimates could have been biased due to the small number of breeders used, and/or the inability to separate common environment and genetic effects.

In a previous study with common carp, we used microsatellite markers for parentage assignment of 240 families produced from 10 dams and 24 sires (Vandeputte et al., 2004). Heritability estimates for weight, standard length and Fulton's condition coefficient were found to range from 0.33 to 0.37 . However, these estimates were obtained with 8-week-old juveniles. Since the results were encouraging and showed a potential for mass selection on growth in common carp, we undertook a first generation of selection to test the effectiveness of selective breeding for growth improvement. We also set up new crosses to estimate the heritability of growth traits in larger fish. As in our previous experiments, we used microsatellite parentage assignment to access family information and avoid environmental effects common to full-sib families and the divergent selected genetic groups.

\section{Materials and methods}

The reproduction and culture of common carp was carried out at the experimental facility of the University of South Bohemia, Research Institute of Fish Culture and Hydrobiology (Vodňany, Czech Republic). The traits of interest were recorded in generation 2 (G2) and generation 3 (G3) fish.

\subsection{Production of $\mathbf{G 1}$}

G1 offspring were produced in May 2001 using a full factorial mating between 24 G0 males and 10 G0 females of the HSM (Hungarian Synthetic Mirror) line (Vandeputte et al., 2004). Fin samples $\left(1 \mathrm{~cm}^{2}\right)$ were taken on all $34 \mathrm{G0}$ parents and kept in tubes filled with $98 \%$ ethanol. A first attempt to produce selected fish from the G1 was done by selecting the fish on length (up, down and control) in July 2001 and April 2002. However, floods that occurred in Vodňany in September 2002 resulted in mixing of the selected batches which were kept in different ponds. We decided to re-start the experiment from the males of this mixed population, as we could assign most of them to their G0 parents, thus allowing one more pedigreed generation compared with re-starting from the base HSM population.

\subsection{Production of $\mathbf{G 2}$}

In May 2003, 147 spermiating males were collected at random from the G1 population, and mated simultaneously with eight suitable G0 HSM females in a full factorial design to establish the G2. Fin samples were collected on all 155 parents (147 G1 males and 8 G0 females), and stored in $98 \%$ ethanol. Only one G0 female was common to both 2001 and 2003 crosses, so the generations can be considered discrete. The details of the mating methodology are given in Vandeputte et al. (2004) and Kocour et al. (2007).

The G2 population was reared as a single batch in one pond under semi-intensive pond management. In September 2003 (one summer), a random sample of 2000 yearlings of G2 population (mean weight 
31g, standard deviation 10.3g) was individually PIT tagged and fin sampled. These G2 tagged fish were reared in one batch in an earthen pond until September 2004 when the 1458 survivors were measured for body length (from the tip of the nose to the end of the caudal peduncle) and body weight.

\subsection{Production of $\mathbf{G} 3$ by divergent selection}

Among the $1458 \mathrm{G} 2$ fish, it happened that $42 \%$ had a deformed mouth, which has a negative impact on growth (Kocour et al., 2006). Only the 848 fish without mouth deformity were then considered as potential candidates for selection. Using September 2004 data, potential male broodfish were identified and pre-selected based on their body length. Body length was chosen as it is highly genetically correlated with body weight (Vandeputte et al., 2004), but easier to measure on many fish in field conditions. The proportion of fish in the Up group was $9.2 \%, 16.2 \%$ in the Control group (average length) and $12 \%$ in the Down group.

The numbers (and hence provisional selection intensities) per group were different, as we feared that less spermiating males would be found among smaller fish in the next spring. In April 2005, 833 fish with normal mouth had survived, and 99 spermiating males $(30 \mathrm{U}, 36 \mathrm{C}, 33 \mathrm{D})$ were identified among the three pre-selected groups. Only males were selected in order to shorten the whole experiment: in the climatic conditions of the Czech Republic, males start to spermiate at the age of 2 or 3 years and they can be used at that age for artificial reproduction, but females mature at the age of 3-4 years and can be used for reproduction at the earliest at the age of 4 years, optimally at 5 years of age. This is why, for this experiment again, we used females from the G0 generation.

On May $19^{\text {th }}, 2005$, the 99 spermiating males were stripped and 96 of them gave enough sperm (30U, 34C, 32D). They were mated in a full factorial design with 8 G0 HSM females (none of which had been used as parent of the G1 and G2 fish), using our usual methodology (Kocour et al., 2007; Vandeputte et al., 2004). The eggs from the three Up, Control and Down groups were mixed and reared as a single batch in one Zuger jar, and then transferred to a resorption trough. At 8 days post-fertilization (dpf), larvae were randomly split in two equal groups of 20,000 larvae and stocked in two ponds of 0.16 ha. Both ponds were harvested in September 2005, and 750 fish were randomly chosen from each pond, measured, PIT-tagged and DNA-sampled. After that, the 1500 tagged fish were put in the same over-wintering pond, and were then treated as a single batch until the end of the second growing season. All surviving fish were individually measured in April 2006 and November 2006.

\subsection{Parentage assignment}

The following fish were genotyped: the $34 \mathrm{G0}$ parents (10 females, 24 males);

the $147 \mathrm{G} 1$ males and the $8 \mathrm{G} 0$ females used as parents for the G2;

812 G2 fish randomly sampled in Sept. 2003;

the $96 \mathrm{G} 2$ males and the $8 \mathrm{G} 0$ females used for producing the $\mathrm{G} 3$;

797 randomly sampled G3 fish (of the total 2x750 fish randomly sampled and measured in Sept. 2005);

All these fish were genotyped for six to eleven microsatellites (Crooijmans et al., 1997): MFW7, MFW9, MFW11, MFW16, MFW18 and MFW26 for all fish, MFW3, MFW12, MFW20, MFW29 and MFW40 for some fish only. Parentage assignment was performed by exclusion with one or two mismatches tolerated using VITASSIGN (Vandeputte et al., 2006). Only fish assigned to a single parental pair were considered for the analysis.

\subsection{Statistical analyses}

The significance of fixed and random effects was evaluated using SAS-GIm in the G3 population. Heritability values were computed for length and weight at each stage $\left(1^{\text {st }}\right.$ summer, $1^{\text {st }}$ spring and $2^{\text {nd }}$ summer), using VCE 5.1.2 (Kovac and Groeneveld, 2003) with an animal model:

$\underline{Y}=\underline{X \beta}+\underline{Z u}+\underline{\mathrm{e}}$

where $\underline{Y}$ is the vector of observations, $\underline{\beta}$ is the vector of fixed effects, including year, pond (in G3) and mouth deformity score (in G2), $\underline{u}$ is the vector of random additive genetic effects, and $\underline{e}$ is the vector of random residual effects. $\underline{X}$ and $\underline{Z}$ are known incidence matrices.

The whole dataset (pedigree from G0 to G3, phenotypes in G2 and G3) was used to estimate heritabilities across generations, while the whole pedigree but only the phenotypes in G2 or in G3 were used to estimate within-generation heritabilities. 
Animals from generations $\mathrm{G} 1$ and $\mathrm{G} 2$ whose parents could not be identified due to imperfect parentage assignment were considered belonging to the base (G0) population. Univariate models were used to estimate heritabilities, bivariate models were used to estimate genetic correlations between length and weight at each stage, and a trivariate model was used to assess genetic correlation between weights (respectively lengths) at different stages (first summer, spring and second summer). Estimated breeding values for all animals in the pedigree were obtained from the solutions for the animal additive genetic values in VCE, using the whole dataset.

The divergence between the selected groups was tested with the following model in SAS-GIm:

$Y_{i j}=\mu+G_{i}+e_{i j}$

Where $\underline{Y}_{i j}$ is the estimated breeding value of fish $\mathrm{j}$ from genetic group $\underline{i}, \underline{\mu}$ is the population mean, $\underline{G}_{i}$ is the fixed effect of genetic group (G0, G1, G2, G3-U, G3-C, G3-D and $\underline{\mathrm{e}}_{\mathrm{ij}}$ is the random residual. Comparison of means between genetic groups was done with the Tukey-Kramer test for multiple comparisons.

Realized response to upwards selection was calculated in two ways, first as twice the difference between the mean breeding values of G3-U and G2, and then as twice the difference between the mean breeding values of G3-U and G3-C. The differences were doubled as in the G3 groups, only the males were selected and then the observed response is half the true selection response. The same type of calculation was done for downwards selection response. Realized heritability was calculated as the ratio of these realized responses (standardized in phenotypic standard deviation units) on the selection differentials.

\section{Results}

\subsection{Selection process}

The coefficients of variation of length and weight at the time of $G 2$ selection ( $2^{\text {nd }}$ summer) were moderately high (24\% for weight and $8.3 \%$ for length). Selection was performed on spermiating males in April 2005 (ca. 2 years of age), based on their length performance after the second summer (in September 2004). The phenotypic means of the three selected groups are given in Table 1. As suspected, mouth deformities had an impact on the size of the fish, and only fish with normal mouth were selected. Then, the selection differentials were also calculated from fish with normal mouth only, and were equivalent to a mass selection intensity of $13 \%(\mathrm{i}=-1.63)$ downwards and $11 \%(\mathrm{i}=1.71)$ upwards.

\subsection{Parentage assignment}

Parentage assignment results were as follows:

126 of the 147 G1 males (85.7\%) could be assigned to a single pair (7 of them with one or two mismatches allowed), the rest being assigned to two or more pairs;

615 individuals in the random sample of $812 \mathrm{G} 2$ fish (75.7\%) could be assigned to a single parental pair (all with perfect match), the rest being assigned to two or more pairs;

63 of the 96 G2 males used for producing the G3 offspring (65.6\%) could be assigned to a single pair (11 of them with one or two mismatches allowed), the rest being assigned to two or more pairs;

647 of the 797 G3 fish (81.2\%) could be assigned to a single pair (7 of them with one or two mismatches allowed), 2 could not be assigned to any pair and the rest was assigned to two or more pairs.

These results allowed us to set up a pedigree including animals from all four generations (G0 to G3). The pedigree included 195 fish without phenotypes (48 G0, 147 G1) and 1321 fish with phenotypes (674 G2, 647 G3).

\subsection{Heritabilities and correlations}

The heritabilities calculated using univariate animal models are given in Table 2. They ranged from 0.31 to 0.44 for body weight and 0.21 to 0.33 for body length when the whole dataset (phenotypes from G2 and G3) was used. At any given age, the genetic correlation between length and weight was $0.97 \pm 0.01$. The genetic correlation between body weights measured at $1^{\text {st }}$ summer and at spring was high $(0.96 \pm 0.01)$, but it was much lower $(0.34-0.41)$ between spring or $1^{\text {st }}$ summer and $2^{\text {nd }}$ summer (Table 3). Genetic correlation between length at first summer and at spring was almost unity 
$(0.996 \pm 0.004)$, and the genetic correlations between length at $2^{\text {nd }}$ summer and at the two younger ages were higher than those seen for weight $\left(0.64 \pm 0.07\right.$ for $1^{\text {st }}$ summer, $0.67 \pm 0.06$ for spring). When we considered weight and length recorded at the same age but in different years (generations) as different traits, we obtained different figures for heritability, higher in G2 than in G3 (Table2).

\subsection{Response to selection}

Phenotypic means of the groups are given in Table 4, and breeding values in the different genetic groups and generations are given in Table 5 . There was no significant variation of the breeding values for any trait, as expected, in the (unselected) G0, G1 and G2 generations. In the G3 generation a difference in breeding values could be seen between the three groups $(U>C>D, \underline{P}<0.05)$ at one summer of age. At spring and at second summer, the Control and Down-selected groups were equivalent, and were outperformed by the Up-selected group $(P<0.05)$. When breeding values were compared between G3 and G2, the Down and Control group had a genetic level equivalent to $G 2$, while the Up-selected group had a higher genetic level $(\underline{P}<0.05)$. This was true for both length and weight, and at all ages. When genetic gain was estimated as the difference between the breeding values of the Up, Down and Control lines, realized heritability estimates were 0.24 , for both upwards and downwards selection. When upwards selection response was estimated as the difference in breeding values between the Up line and G2, the corresponding realized heritability estimate was 0.34 . When the same was done for downwards selection, realized heritability was 0.14 only.

\section{Discussion}

\subsection{Parentage assignment}

A total of 1451 out of the 1852 fish genotyped could be assigned to a single parent pair (78.3\%). This figure is relatively low compared to other parentage assignment studies in fish (usually in the 90-99\% range, e.g. Fishback et al., 2002; Norris and Cunningham, 2004; Vandeputte et al., 2004; Wesmajervi et al., 2006). However, we used large mating schemes in G2 and G3 (147 males x 8 females and 96 males $\times 8$ females, respectively). In such cases with many potential parents, it is not unusual to have lower assignment rates (e.g. $73.5 \%$ in red sea bream with 250 potential parents, Perez-Enriquez et al., 1999). It must be noted also that the number of non assigned fish is very low (2 fish in G3), and that the number of fish for which mismatches are needed to achieve unique assignment is also low (25 fish in total), which is indicative of a low genotyping error rate (Vandeputte et al., 2006). Therefore, the lack of assignment power is essentially due to an insufficient resolution of the microsatellite loci set in crosses with many parents and combinations, possibly combined with the fact that domesticated common carp strains commonly have a low allelic richness, due to their long empirical breeding history (Kohlmann et al., 2005). Therefore, the pedigree used should comprise only a limited proportion of mis-assigned fish, and therefore be suitable for quantitative genetics studies. If present, a lack of accuracy in the molecular pedigree should anyway lead to an under-estimation of heritabilities and larger standard errors (Milner et al., 2000). If microsatellites were to be used for family based selection in common carp however, it would be necessary to improve the marker set (more loci, more variable), as more than $20 \%$ unassigned fish would not be economically acceptable.

\subsection{Heritabilities and correlations}

The heritabilities for growth estimated in the present study with the whole dataset (0.21-0.44) are in the usual range for common carp, (Nagy et al., 1980; Nenashev, 1969; Nenashev, 1966; Smisek, 1981; Tanck et al., 2001 - see review by Vandeputte, 2003). They are very similar to those we found for 8-weeks weight in the same HSM population (0.33, Vandeputte et al., 2004), but much lower than the one we estimated for weight at 3 summers of age $(0.70$, Kocour et al., 2007). However, it must be noted that heritability of weight estimated solely in the $\mathrm{G} 2$ generation gives values comparable to this latter one (0.48-0.67). The fish used by Kocour et al. (2007) were fish from the G2 generation, so this similarity could be expected. This global heritability estimate of $0.21-0.44$, confirmed over generations, places common carp in the usual range of heritability for growth in commercial aquaculture species (reviewed by Gjedrem and Olesen, 2005). This value clearly leaves room for selective breeding for growth in the common carp. 
We could see that the genetic correlation between growth measurements (weight or length) in first and second summer was not high (0.3-0.4 for weight, 0.6-0.7 for length). When we consider traits in G2 and in $\mathrm{G} 3$ as different traits, the heritability estimates are never as low as in first summer in G3, where two environments (ponds) were used for first summer growth. The low heritability could be explained if the offspring from the different sires were ranked differently in both ponds. Unfortunately, the small family size (6.8 offspring/sire on average, or 3.4 in each pond) did not allow us to test for a sire pond interaction with enough power. Nevertheless, genotype by environment (GxE) interactions are well documented in common carp, at least at the population level, where it has been shown that different populations may be re-ranked when tested in different environments (Gross and Wohlfarth, 1994; Moav et al., 1975; Wohlfarth et al., 1983). Therefore, the existence of such interactions at the family level could be a possibility, although here, we did not try to generate GxE effects, as we used most of the time only one pond with all genotypes mixed within.

Correlations between sizes at different ages were low to moderate. Then, pre-selection of young fish might not be effective and might bring only moderate improvement to the weight at commercial size. A second argument for this is the possibility of low survival (due to severe overwintering, predation, diseases etc.) of fish in ponds: here in $\mathrm{G} 3$, at the end of the $2^{\text {nd }}$ summer, only 479 of the 1500 fish tagged at $1^{\text {st }}$ summer were still alive - only $32 \%$ survival. It would seem more rational to wait for older fish to be selected when less inadvertent mortalities occur. However, pre-selection of younger fish might be still cost-effective considering the difficulties connected to later selection (feeding costs, higher number of fish to be reared, manipulation and transport problems with bigger fish, number and size of ponds needed etc.). Overall, in Central European conditions we recommend selection of the common carp at two years of age (300-600 g).

The genetic correlation between length and weight at a given age was close to unity, as usual in fish species, so selection for increased weight can be performed on length, which is much easier to measure in the field on a large number of fishes. However, heritability of length (except in G3) seems to be slightly lower than heritability of weight, and therefore it might be more advantageous, even if less practical, to select on weight rather than on length.

\subsection{Response to selection}

The absolute response to selection observed was low. No significant response to downwards selection was observed, when compared with the genetic level of the G2 generation. This is the exact opposite of the results obtained in the first generation of the Israeli divergent selection experiment (Moav and Wohlfarth, 1976). One problem about the $2^{\text {nd }}$ summer $\mathrm{G} 3$ data is that they were obtained on a small fish sample (62 to 72 genotyped fish per group), due to the mortality from $1^{\text {st }}$ to $2^{\text {nd }}$ summer. Therefore, the response estimates were quite imprecise in the $2^{\text {nd }}$ summer. The realized heritability values for upwards selection (0.24-0.34) are in the same range as the animal model values (0.21-0.33 for length). Besides this, we have to keep in mind that the present results for response to selection were obtained in communal rearing, with all three genetic groups $(U, C, D)$ mixed in the same pond. However, it was shown that communal testing could magnify the differences between genetic groups in common carp (Moav and Wohlfarth, 1974), and so the differences observed here (although moderate) could be over-estimated.

The advantage of rearing the different groups in the same pond from the beginning and retrieving their origin with microsatellites is that it allowed us to test for selection response in the first generation of selection, without common environmental effects, and with some chances to see the small differences generated. If we were to test the difference between genotypes in separate ponds, being able to detect differences in weight around $10 \%$ of the mean may require more than 20 replicated ponds, a number that may be lowered to 4-5 replicates using an internal control line (Gross and Wohlfarth, 1994; Vandeputte et al., 2002).

With a mean heritability value around 0.25 , mass selection for growth in common carp should lead to a gain of $12 \%$ weight and $4 \%$ length by generation, when selecting the best $10 \%$ of the populations. The practical generation interval of common carp in the Czech Republic is 4.5 years (4 years for males, 5 years for females): even if males spermiate from 2-3 years of age, they are routinely used for reproduction from the age of 4 years (rarely from 3 years), and females are usually used from the age of 5 years (rarely from 4 years). Then, the annual genetic gain in weight could be around 2.7-3 \%. Due to the moderate heritability value, family selection could also be considered, but it cannot be done easily in separate ponds due to pond effects, and doing it in mixed families with genotyping would be an excessive cost. Therefore, mass selection could be a reasonable option with complementary selection on quality traits from measurements on live animals, such as fat-meter value to control the level of muscular fat, and selection for reduced head length to increase fillet yield (Kocour et al., 2007). 
Still, this would be a long-term project of 10-15 years with sustained investment necessary before a significant improvement (30-40\%) could be seen by an individual farmer, because of the large year-toyear and pond-to-pond variability. Still, the global impact averages on many farms would be immediately positive. The precise impact of GxE interactions on the genetic gain would also have to be more precisely evaluated, using larger samples in different rearing conditions.

Finally, considering the possibility to genetically improve growth in common carp, the following question remains: the total weight of fish harvested from a pond depends on the combination of the natural pond productivity, supplemental food given and survival rate of stocked fish (e.g. Szumiec, 1990). Is it then sure that carps with improved growth would increase the global pond productivity under semi-intensive pond management? It will be certain only if there is a correlated response in feed efficiency. However, this correlation seems to be vary a lot among species: non-existent in brown trout (Sanchez et al., 2001), moderate in rainbow trout (Kause et al., 2006), and higher in Atlantic salmon (Thodesen et al, 1999). So, carp with improved growth will need to be accompanied with adapted management procedures (e.g. lower density and/or higher supplemental food) to express their potential. Another possibility would be to improve flesh yield, which seems feasible on the basis of recent results (Kocour et al., 2007). In this case, the objective would not be to improve pond productivity, but to improve the quantity of edible flesh from a given pond production.

\section{Acknowledgements}

The authors wish to thanks the staff of the hatchery at USB RIFCH in the Czech Republic for active participation in the production of the experimental fish. This work was supported by the project of National Agency for Agricultural Research in the Czech Republic, no. QF4117, by Research plan of USB RIFCH no. MSM6007665809 and funds from INRA Animal Genetics Department, as well as funding from France-Czech Republic bilateral programs BARRANDE $n^{\circ}$ 03218RF, 07508SA and 2004-044-2.

\section{References}

Bakos, J., Gorda, S., 1995. Genetic improvement of common carp strains using intraspecific hybridization. Aquaculture 129, 183-186.

Bialowas, H., 1991. Possibilities of application of the heterosis effect in commercial production of common carp (Cyprinus carpio L.). 1. Production of fingerlings. Acta Hydrobiol. 33, 319-334.

Cherfas, N.B., Gomelsky, B., Ben-Dom, N., Joseph, D., Cohen, S., Israel, I., Kabessa, M., Zohar, G., Peretz, Y., Mires, D., Hulata, G., 1996. Assessment of all-female common carp progenies for fish culture. Isr. J. Aquacult. -Bamidgeh 48, 149-157.

Crooijmans, R.P.M.A., Bierbooms, V.A.F., Komen, J., Van der Poel, J.J., Groenen, M.A.M., 1997. Microsatellite markers in common carp (Cyprinus carpio L.). Anim. Genet. 28, 129-134.

FAO, 2003. Aquaculture production 2001. FAO Yearbook of Fisheries Statistics 92/2.

Fishback, A.G., Danzmann, R.G., Ferguson, M.M., Gibson, J.P., 2002. Estimates of genetic parameters and genotype by environment interactions for growth traits of the rainbow trout (Oncorhynchus mykiss) as inferred using molecular pedigrees. Aquaculture 206, 137-150.

Gjedrem, T., Olesen, I., 2005. Basic statistical parameters. In: Gjedrem, T. (Ed.), Selection and Breeding Programs in Aquaculture. Springer, Dordrecht, The Netherlands, pp. 45-72.

Gross, R., Wohlfarth, G.W., 1994. Use of genetic markers in growth testing of common carp, Cyprinus carpio L., carried out over 2 or 3 year cycles. Aquacult. Fish. Manage. 25, 585-599.

Horvath,L., Tamas, G., Seagrave, C., 1992. Carp and pond fish culture. Blackwell Scientific Publications Ltd., UK, 158 pp.

Hulata, G., 1995. A review of genetic improvement of the common carp (Cyprinus carpio L.) and other cyprinids by crossbreeding, hybridization and selection. Aquaculture 129, 143-155.

Kause, A., Tobin, D., Houlihan, D.F., Martin, S.A.M., Mantysaari, E.A., Ritola, O., Ruohonen, K., 2006. Feed efficiency of rainbow trout can be improved through selection: Different genetic potential on alternative diets. J. Anim. Sci. 84, 807-817.

Kinghorn, B.P., 1983. A review of quantitative genetics in fish breeding. Aquaculture 31, 283-304. 
Kocour, M., Gela, D., Rodina, M., Linhart, O., 2005. Testing of performance in common carp Cyprinus carpio L. under pond husbandry conditions I: top-crossing with Northern mirror carp. Aquacult. Res. 36, 1207-1215.

Kocour, M., Linhart, O., Gela, D., 2003. Results of comparative growing test of all-female and bisexual population in two-year-old common carp (Cyprinus carpio L.). Aquacult. Int. 11, 369-378.

Kocour, M., Linhart, O., Vandeputte, M., 2006. Mouth and fin deformities in common carp: is there a genetic basis? Aquacult. Res. 37, 419-422.

Kocour, M., Mauger, S., Rodina, M., Gela, D., Linhart, O., Vandeputte, M., 2007. Heritability estimates for processing and quality traits in common carp (Cyprinus carpio L.) using a molecular pedigree. Aquaculture 270, 43-50.

Kohlmann, K., Kersten, P., Flajshans, M., 2005. Microsatellite-based genetic variability and differentiation of domesticated, wild and feral common carp (Cyprinus carpio L.) populations. Aquaculture 247, 253-266.

Kovac, M., Groeneveld, E., 2003. VCE5 user's guide and manual version 5.1. Department of Animal Sciences, University of Ljubljana, Ljubljana, 68 pp.

Lynch,M., Walsh, B., 1998. Genetics and analysis of quantitative traits. Sinauer Associates, Sunderland, MA, $980 \mathrm{pp}$.

Milner, J.M., Pemberton, J.M., Brotherstone, S., Albon, S.D., 2000. Estimating variance components and heritabilities in the wild: a case study using the 'animal model' approach. J. Evol. Biol. 13, 804813.

Moav, R., Hulata, G., Wohlfarth, G.W., 1975. Genetic differences between the Chinese and European races of the common carp. I. Analysis of genotype-environment interactions for growth rate. Heredity 34, 323-340.

Moav, R., Wohlfarth, G.W., 1974. Magnification through competition of genetic differences in yield capacity in carp. Heredity 33, 181-202.

Moav, R., Wohlfarth, G.W., 1976. Two way selection for growth rate in the common carp (Cyprinus carpio L.). Genetics 82, 83-101.

Nagy, A., Csanyi, V., Bakos, J., Horvath, L., 1980. Development of a short-term laboratory system for the evaluation of carp growth in ponds. Bamidgeh 32, 6-15.

Nenashev, G.A., 1969. Heritability of some selective characters in Ropsha carp (Russian). Izvestija Gosud. Nauchno-issled. Inst. Ozern. Recn. Rybn. Kos. (GosNIORKh) 65, 185-195.

Nenashev, G.A., 1966. The determination of heritability of different characters in fishes. Genetika 11, 100-108.

Norris, A.T., Cunningham, E.P., 2004. Estimates of phenotypic and genetic parameters for flesh colour traits in farmed Atlantic salmon based on multiple trait animal model. Livest. Prod. Sci. 89, 209-222.

Perez-Enriquez, R., Takagi, M., Taniguchi, N., 1999. Genetic variability and pedigree tracing of a hatchery-reared stock of red sea bream (Pagrus major) used for stock enhancement, based on microsatellite DNA markers. Aquaculture 173, 413-423.

Sanchez, M.P., Chevassus, B., Labbe, L., Quillet, E., Mambrini, M., 2001. Selection for growth of brown trout (Salmo trutta) affects feed intake but not feed efficiency. Aquat. Liv. Resour. 14, 41-48.

Smisek, J., 1981. The effect of gene pool on the performance and conformation of filial generations of carp fry from line crossing. Bull. VURH Vodnany 17, 3-11.

Szumiec, M.A., 1990. Stochastic model of carp fingeling growth. Aquaculture 91, 87-99.

Tanck, M.W.T., Vermeulen, H., Bovenhuis, H., Komen, J., 2001. Heredity of stress-related cortisol response in androgenetic common carp (Cyprinus carpio L.). Aquaculture 199, 283-294.

Thodesen, J., Grisdale-Helland, B., Stale, J., Gjerde, B., 1999. Feed intake, growth and feed utilization of offspring from wild and selected Atlantic salmon (Salmo salar). Aquaculture 180, 237-246.

Vandeputte, M., 2003. Selective breeding of quantitative traits in the common carp (Cyprinus carpio L.): a review. Aquat. Liv. Resour. 16, 399-407.

Vandeputte, M., Kocour, M., Mauger, S., Dupont-Nivet, M., De Guerry, D., Rodina, M., Gela, D., Vallod, D., Chevassus, B., Linhart, O., 2004. Heritability estimates for growth-related traits using microsatellite parentage assignment in juvenile common carp (Cyprinus carpio L.). Aquaculture 235, 223-236.

Vandeputte, M., Mauger, S., Dupont-Nivet, M., 2006. An evaluation of allowing for mismatches as a way to manage genotyping errors in parentage assignment by exclusion. Mol. Ecol. Notes 6, 265-267.

Vandeputte, M., Peignon, E., Vallod, D., Haffray, P., Komen, J., Chevassus, B., 2002. Comparison of growth performances of three French strains of common carp (Cyprinus carpio) using hemi-isogenic scaly carp as internal control. Aquaculture 205, 19-36.

Wesmajervi, M.S., Westgaard, J.I., Delghandi, M., 2006. Evaluation of a novel pentaplex microsatellite marker system for paternity studies in Atlantic cod (Gadus morhua L.). Aquacult. Res. 37, 1195-1201. 
Wohlfarth, G.W., 1993. Heterosis for growth rate in common carp. Aquaculture 113, 31-46.

Wohlfarth, G.W., Moav, R., Hulata, G., 1983. A genotype-environment interaction for growth rate in the common carp, growing in intensively manured ponds. Aquaculture 33, 187-195. 
Table1. Numbers and size of G2 carp at two summers, before and after divergent selection. S.D.= standard deviation

\begin{tabular}{|c|c|c|c|}
\hline & Number of fish & $\begin{array}{l}\text { Length } \\
\text { at } \quad 2^{\text {nd }} \\
\mathrm{mm}(S . D .)\end{array}$ & $\begin{array}{l}\text { Selection differential } \\
\text { (Length phenotypic } \\
\text { S.D. units) }\end{array}$ \\
\hline Fish with deformed mouth & 610 & $234.0(20.7)$ & - \\
\hline Fish with normal mouth & 848 & 249.4 (19.3) & - \\
\hline Spermiating Up fish & 30 & $282.4(7.5)$ & +1.71 \\
\hline Spermiating Control fish & 36 & $250.6(5.3)$ & +0.06 \\
\hline Spermiating Down fish & 33 & $218.1(9.4)$ & -1.63 \\
\hline
\end{tabular}

Table 2. Heritabilities ( \pm S.E.) for body weight and length at different ages in common carp, using univariate animal models in VCE5, four generations of pedigree and two generations of phenotypes ( $G 2$ and $G 3$, whole datatset) or just one generation of phenotypes (G2 only or G3 only).

\begin{tabular}{lllllll}
\hline & \multicolumn{2}{l}{ Whole dataset } & G2 only & & G3 only & \\
\hline Age & Weight & Length & Weight & Length & Weight & Length \\
\cline { 2 - 7 } $1^{\text {st }}$ summer & $0.31 \pm 0.04$ & $0.21 \pm 0.03$ & $0.61 \pm 0.03$ & $0.39 \pm 0.04$ & $0.18 \pm 0.06$ & $0.25 \pm 0.07$ \\
Spring & $0.33 \pm 0.04$ & $0.26 \pm 0.03$ & $0.67 \pm 0.03$ & $0.46 \pm 0.04$ & $0.20 \pm 0.07$ & $0.27 \pm 0.08$ \\
$2^{\text {nd }}$ summer & $0.44 \pm 0.05$ & $0.33 \pm 0.04$ & $0.48 \pm 0.03$ & $0.36 \pm 0.05$ & $0.37 \pm 0.13$ & $0.40 \pm 0.13$ \\
\hline
\end{tabular}

Table 3. Heritabilities \pm S.E. (bold), genetic correlations \pm S.E. (italics) from trivariate animal models, and phenotypic correlations (plain) for body weight and body length after $1^{\text {st }}$ summer, at spring and after second summer in common carp, using phenotypes from $\mathrm{G} 2$ and $\mathrm{G} 3$ and the pedigree from G0 to $\mathrm{G} 3$.

\begin{tabular}{lllll}
\hline \multirow{4}{*}{ Weight } & & $1^{\text {st }}$ summer & spring & $2^{\text {nd }}$ summer \\
\cline { 3 - 5 } & $1^{\text {st }}$ summer & $\mathbf{0 . 3 2 \pm 0 . 0 3}$ & $0.96 \pm 0.01$ & $0.41 \pm 0.08$ \\
& spring & 0.95 & $\mathbf{0 . 2 9 \pm 0 . 0 3}$ & $0.34 \pm 0.08$ \\
\multirow{3}{*}{ Length } & $2^{\text {nd }}$ summer & 0.65 & 0.71 & $\mathbf{0 . 4 6 \pm 0 . 0 4}$ \\
\cline { 2 - 5 } & $1^{\text {st }}$ summer & $\mathbf{0 . 2 0 \pm 0 . 0 3}$ & $1.00 \pm 0.00$ & $0.64 \pm 0.07$ \\
& spring & 0.97 & $\mathbf{0 . 2 2 \pm 0 . 0 3}$ & $0.67 \pm 0.06$ \\
& $2^{\text {nd }}$ summer & 0.68 & 0.71 & $\mathbf{0 . 2 8} \pm \mathbf{0 . 0 4}$ \\
\hline
\end{tabular}

Table 4. Phenotypic data (mean values with standard deviation in brackets) of genotyped offspring from selected groups of carp in G3.

\begin{tabular}{|c|c|c|c|c|c|c|c|c|c|}
\hline & \multicolumn{2}{|c|}{$1^{\text {st }}$ summer } & \multicolumn{3}{|c|}{ Spring } & \multicolumn{3}{|c|}{$2^{\text {nd }}$ summer } & \multirow[b]{2}{*}{$\begin{array}{l}\text { Length } \\
(\mathrm{mm})\end{array}$} \\
\hline & $\underline{\mathrm{n}}$ & $\begin{array}{l}\text { Weight } \\
\text { (g) }\end{array}$ & $\begin{array}{l}\text { Length } \\
(\mathrm{mm})\end{array}$ & $\underline{\mathrm{n}}$ & $\begin{array}{l}\text { Weight } \\
\text { (g) }\end{array}$ & $\begin{array}{l}\text { Length } \\
(\mathrm{mm})\end{array}$ & $\underline{\mathrm{n}}$ & $\begin{array}{l}\text { Weight } \\
\text { (g) }\end{array}$ & \\
\hline $\begin{array}{l}\text { Up } \\
\text { selected }\end{array}$ & 202 & $\begin{array}{l}32.1 \\
(11.4)\end{array}$ & $\begin{array}{l}93.0 \\
(12.7)\end{array}$ & 103 & $\begin{array}{l}32.4 \\
(9.7)\end{array}$ & $\begin{array}{l}97.0 \\
(9.9)\end{array}$ & 66 & 703 (173) & $\begin{array}{l}306 \\
(26)\end{array}$ \\
\hline Control & 225 & $\begin{array}{l}30.7 \\
(10.5)\end{array}$ & $\begin{array}{l}92.0 \\
(11.2)\end{array}$ & 112 & $\begin{array}{l}30.8 \\
(8.4)\end{array}$ & $\begin{array}{l}95.6 \\
(9.1)\end{array}$ & 72 & $\begin{array}{l}659 \\
(152)\end{array}$ & $\begin{array}{l}300 \\
(22)\end{array}$ \\
\hline $\begin{array}{l}\text { Down } \\
\text { selected }\end{array}$ & 220 & $\begin{array}{l}30.4 \\
(9.7)\end{array}$ & $\begin{array}{l}91.5 \\
(11.8)\end{array}$ & 110 & $\begin{array}{l}31.1 \\
(9.4)\end{array}$ & $\begin{array}{l}95.9 \\
(9.7)\end{array}$ & 62 & $\begin{array}{l}670 \\
(161)\end{array}$ & $\begin{array}{l}299 \\
(23)\end{array}$ \\
\hline
\end{tabular}


Table 5. Differences between genetic groups for Estimated Breeding Values from the animal model with the whole dataset, estimated for body weight (BW) and body length (BL) at 1summer, spring and 2 summers of age. Within each line, means with the same superscript are not significantly different (Tukey-Kramer test, $\underline{P}>0.05)$.

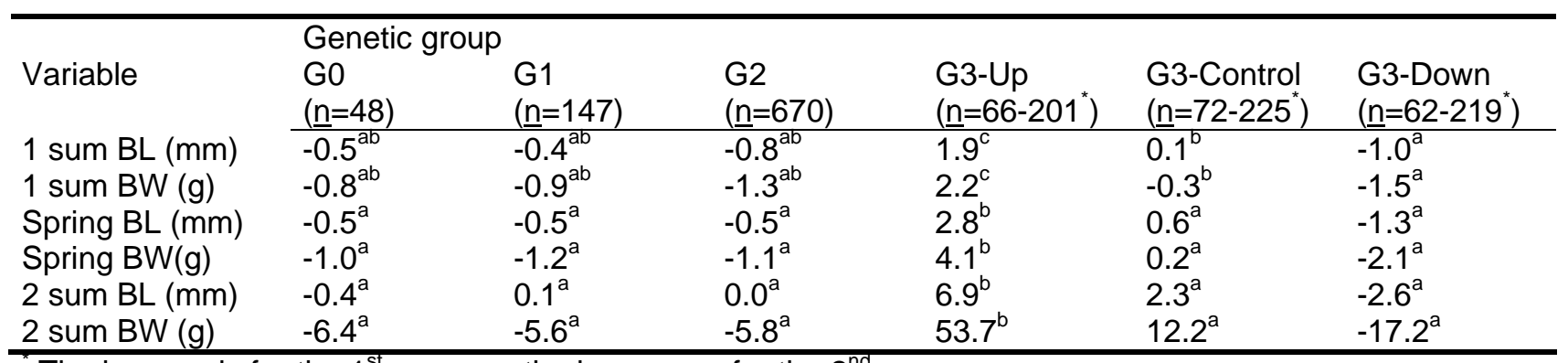

"The larger $\underline{n}$ is for the $1^{\text {st }}$ summer, the lower one for the $2^{\text {nd }}$ summer. 